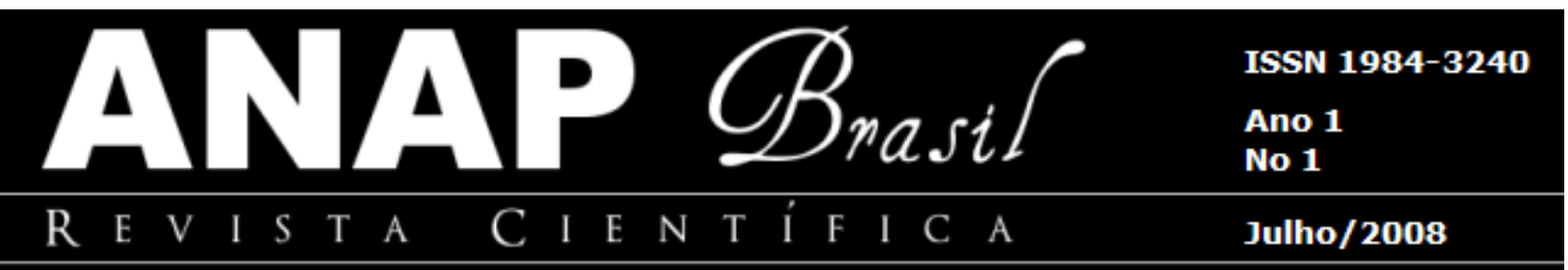

\title{
ENFOQUE EPISTEMOLÓGICO SOBRE SABERES E PRÁTICAS AMBIENTAIS NA FORMAÇÃO INICIAL DE PROFESSORES
}

\author{
Ademar Vieira dos Santos ${ }^{1}$
}

\section{Evandro Ghedin 2}

RESUMO: Pesquisa com o objetivo de entender a concepção que os professores em formação do Curso Normal Superior do projeto PROFORMAR (programa de formação de professores) da Universidade do Estado do Amazonas (UEA) possuíam sobre meio ambiente, as problemáticas ambientais da atualidade e as suas práticas pedagógicas nas escolas públicas. A pesquisa se deu em duas etapas: antes e após o término do módulo de "Educação Ambiental". Com o propósito de entender se os conhecimentos e as novas práticas pedagógicas que os professores adquiririam, possibilitam aos seus aprendizes, construir meios para superar de forma racional as problemáticas ambientais que mais lhes incomodam. A pesquisa desenvolveu-se com a participação de trezentos professores, que responderam questionários com questões abertas e fechadas. Como resultado, foi possível observar que antes do módulo, aqueles docentes concebiam o meio ambiente como sendo uma questão exclusivamente ecológica. Possuíam uma representação antropocêntrica. Após o módulo, cinqüenta por cento dos docentes dizem ver o meio ambiente como sendo uma questão também socioambiental. Antes do módulo, setenta por cento disseram construir conteúdos a partir do cotidiano dos estudantes. Após o módulo, eles dizem ter descoberto muitas outras referências para trabalhar a questão ambiental. $\mathrm{Na}$ medida em que se procurou entender as representações e as práticas pedagógicas dos professores em formação, criou-se a possibilidade de construção de soluções para muitas das problemáticas ambientais, e a possibilidade de oferecer subsídios teóricos e metodológicos para outras pesquisas no campo da educação ambiental.

Palavras-chave: Formação de Professores. Educação Ambiental. Epistemologia Ambiental.

\footnotetext{
${ }^{1}$ Mestrando em Educação Ambiental pela Universidade de Lion. Professor na UEA e na rede Pública estadual. Graduado em Pedagogia. Especialista em Metodologia do Ensino Superior.

2 Doutor em Filosofia da Educação pela USP. Professor da UEA e FSDB. Licenciado em Filosofia. Especialista em Filosofia. Especialista em Antropologia na Amazônia. Mestre em Educação pela UFAM .
} 


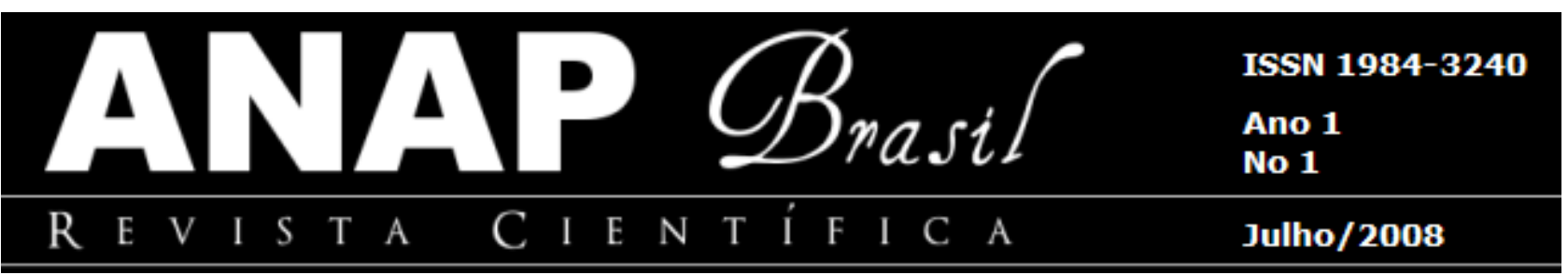

\section{INTRODUÇÃO}

A pesquisa foi realizada na Escola Normal Superior com professores em formação do Curso Normal Superior (PROFORMAR) da Universidade do Estado do Amazonas (UEA). OPROFORMAR é um curso de formação de professores em licenciatura plena, com habilitação para o ensino nas séries iniciais do Ensino Fundamental, é ainda destinado aos professores das redes estadual e municipal, portadores de diploma do curso de magistério, conforme art. 62 da lei 9.394 (LDB).

O curso funciona através de um circuito de TV com aulas transmitidas ao vivo diretamente dos estúdios da UEA instalado no prédio Samuel Bechimol à Rua Leonardo Malcher, no Bairro de Praça 14. As aulas são produzidas por uma equipe de professores doutores e mestres (chamados de professores titulares) e assistidas por professores em formação e mediadas por professores assistentes distribuídos um em cada sala de aula.

No edifício "Mário Ypiranga Monteiro" funcionavam, no período da pesquisa, quatorze (14) salas de aula com trinta e cinco (35) professores em formação em cada uma delas.

Os professores em formação dispõem de um material didático contendo os conteúdos da disciplina e, de modo geral, faziam-se três avaliações em cada módulo, duas provas objetivas com consulta e uma prova dissertativa, também com consulta, no final do oferecimento da disciplina. As salas onde os professores assistem aulas transmitidas do estúdio são equipadas com TV, vídeo, telefone e computadores conectados á uma central de atendimento chamada de "Call Center" através de satélite. Após cada aula os professores desenvolvem uma atividade didática numa temática relacionada ao conteúdo ministrado. Na seqüência, os professores em formação, por vinte minutos, debatem, estudam e preparam material em relação ao conteúdo ou em relação às indicações dos professores titulares. Essas atividades são acompanhadas e orientadas pelos professores assistentes.

A pesquisa se deu em duas fases: antes e após o módulo de Educação Ambiental desenvolvido no PROFORMAR. 


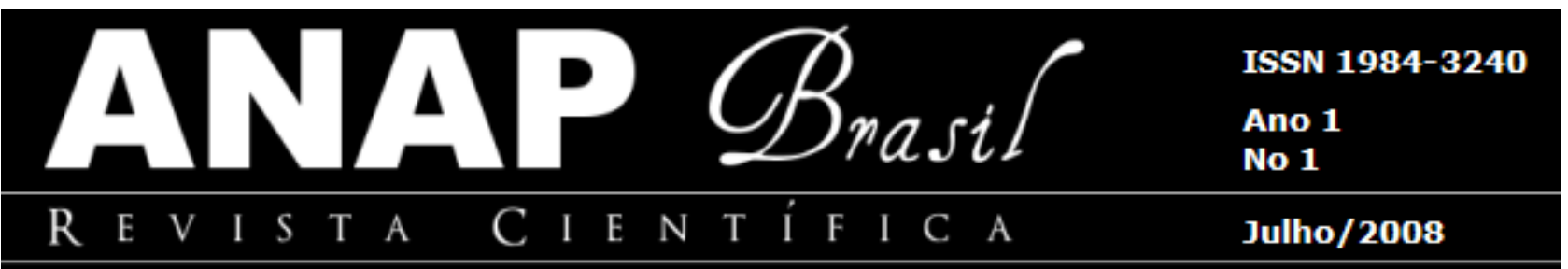

\section{CONCEPÇÃO DE MEIO AMBIENTE DOS PROFESSORES EM FORMAÇÃO ANTES DE CURSAREM O MÓDULO DE EDUCAÇÃO AMBIENTAL}

A concepção dos professores demonstrada nesse primeiro momento da pesquisa nos conduz à percepção da existência de um comportamento antropocêntrico daqueles profissionais em formação em relação à forma como concebem a questão ambiental e as suas práticas como professores das séries iniciais do Ensino Fundamental, isto porque supõem estarem eles no centro do meio ambiente, mas não se vêem como partícipes deste processo, consideram-se, alheios as suas próprias identidades.

É possível perceber que há por parte deles uma tendência em polarizar ou compartimentabilizar ecologicamente o meio ambiente, sempre excluindo o ser humano. Ignoram que o meio ambiente se constitui não só do meio geográfico, biológico ou ecológico, mas também do meio cósmico e do social, com todas as suas instituições, com suas problemáticas, com suas culturas e seus valores.

Na convivência com os professores em formação e na observação do pesquisador, este tipo de comportamento se deve ao fato das inúmeras dúvidas que os professores em formação demonstraram possuir sobre a questão ambiental, pois muitos se demonstraram tímidos ao receber o questionário e até se desculparam dizendo que não possuíam muitos conhecimentos sobre esse assunto e que iam responder da maneira que sabiam.

A postura dos professores em formação demonstrada nesse primeiro momento da pesquisa é preocupante e se deve a concepção conservacionista biológica tradicional que ao longo da história tem dominado o pensamento ambiental no Brasil.

O desafio está em repensar a educação ambiental em sua totalidade. Enfrentando, a fragmentação e o tradicionalismo biológico e ecológico, que permeiam o pensamento ambiental. Para isto, é mister a construção de um novo modelo epistemológico pensado a partir da história, da estrutura de classe e da cultura dos cidadãos, e que lhes sirva de fundamento na construção de uma concepção ambiental que possa dar conta da complexidade na sua totalidade, onde os sujeitos possam se incluir, libertando-se de uma 


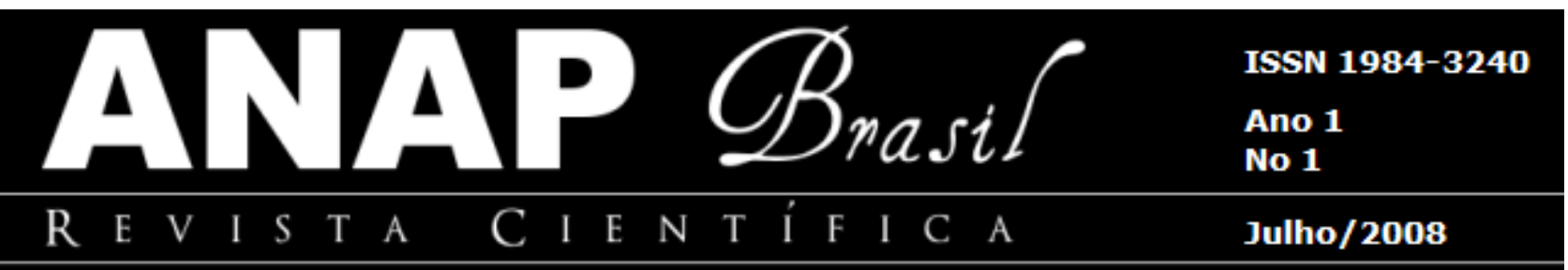

vida reprodutora, percebendo que existem possibilidades de construir alternativas na sua própria realidade.

A ciência moderna, nascida com Newton, Copérnico e Galileu Galilei, não soube o que fazer da complexidade. A estratégia foi reduzir o complexo ao simples. Por exemplo, ao contemplar a natureza, ao invés de analisar a teia de relações complexas existentes, os cientistas tudo compartimentaram e isolaram. Assim, começaram a estudar só as rochas, ou só as florestas, ou só os animais, ou só os seres humanos. E, nos seres humanos, só os olhos, só o coração, só os ossos, etc, Desse estudo, nasceram os vários saberes particulares e as várias especialidades. Ganhou-se em detalhe, mas perdeu-se a totalidade ( BOFF,1995 p.59).

A concepção fragmentada dos professores sobre meio ambiente pode resultar em impedimento de muitas conquistas ambientais e socioambientais há tempo sonhada pela sociedade amazonense como: desenvolvimento sustentável e, por conseguinte a emancipação social, visto que o conhecimento ambiental que lhes foi oferecido não Ihes possibilitou uma compreensão mais holística do que é meio ambiente.

\section{CONCEPÇÕES SOBRE A PROBLEMÁTICA AMBIENTAL NA VISÃO DOS DOCENTES PESQUISADOS}

Percebe-se que existia muita insegurança por parte daqueles docentes no momento de expor suas concepções sobre a problemática ambiental. Ao analisarmos as especificações dos que afirmam que a questão é socioambiental, verificamos que (72\%) setenta e dois por cento daqueles mesmos docentes se contradizem ao afirmar que a questão ambiental é uma problemática de preservação e conservação do espaço natural. Continuam assim se excluindo, apontando o meio ambiente como algo lá adiante, como um problema dos outros.

Esses professores em formação não conseguiram perceber que são parte de um problema, que de certo modo, não conseguiram conceituar e ainda têm dificuldade em entender, em virtude da sua complexidade na atualidade. Superar essa visão 


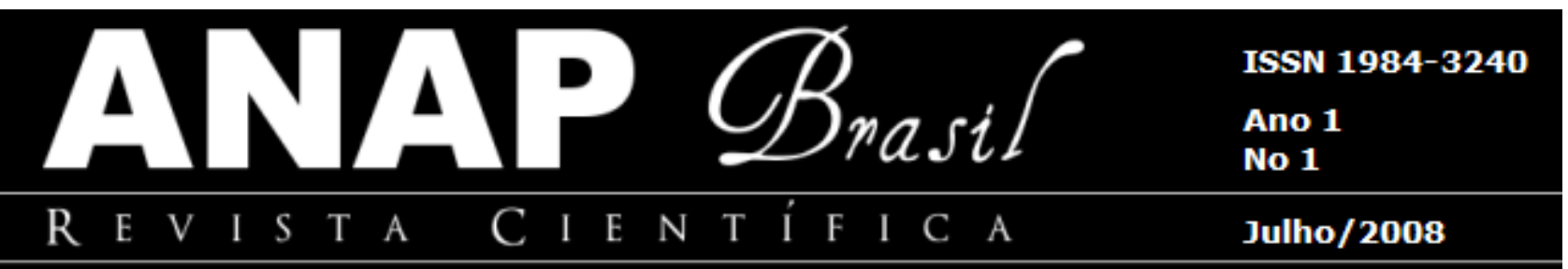

ultrapassada requer o compromisso dos educadores, no sentido de construir bases epistemológicas fundamentadas nas ciências sociais, de modo que se possa explicar a complexidade atual, que na realidade não é ecológica, e sim socioambiental.

\section{OS CONHECIMENTOS DE MEIO AMBIENTE DOS PROFESSORES EM FORMAÇÃO ANTES DE CURSAREM O MÓDULO DE EDUCAÇÃO AMBIENTAL}

Ao analisarmos os resultados percebemos que livros, jornais e revista são as fontes mais procuradas pelos professores em formação, mas ao perguntarmos de onde buscavam conteúdos para trabalhar com os seus alunos, a maioria deles afirmou que os retiram apenas de jornais, revistas e do cotidiano dos alunos.

Os jornais e as revistas são importantes, mas os professores precisam estar conscientes de que precisam buscar leituras mais específicas que estão dispostas nos próprios livros, na internet, suplementos impressos e outros, como também precisam que Ihes sejam oferecidas oportunidades e condições para participar de eventos tipo: palestras e seminários.

O que mais preocupou foi o fato de descobrimos que muitos daqueles professores em formação não possuíam o menor conhecimento sobre o acervo de educação ambiental existente na própria biblioteca da Escola Normal Superior onde estudam. Para trabalharem a questão ambiental a partir do cotidiano dos estudantes é indiscutivelmente necessário que os professores tenham conhecimentos ambientais mais significativos encontrados nos livros didáticos, considerando-se a necessidade que se tem de sociabilizar os saberes ambientais já elaborados a realidade ambiental dos estudantes, com a finalidade de transformar esses saberes do senso comum em conhecimentos ambientais científicos capazes de oferecer respostas racionais às diferentes problemáticas ambientais e socioambientais vividas pelos estudantes e pela sociedade amazonense. 


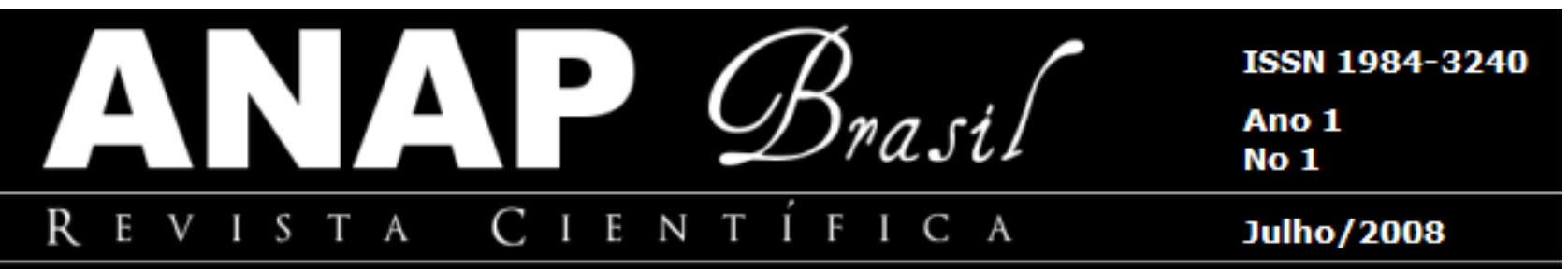

\section{CONTEÚDOS QUE TRABALHAVAM OS PROFESSORES EM FORMAÇÃO EM SUAS PRÁTICAS EDUCATIVAS ANTES DE CURSAREM O MÓDULO DE EDUCAÇÃO AMBIENTAL}

Vários professores em formação afirmam construir conteúdos do cotidiano para trabalhar com os seus aprendizes, mas as suas leituras se concentram em torno de periódicos semanais. Poucos leram livros sobre as questões ambientais e nenhum demonstrou conhecer as abordagens postas nos Parâmetros Curriculares Nacionais em relação às questões ambientais. Em conseqüência disso, não conseguem deixar explícito as metodologias $\mathrm{e}$ as pedagogias que utilizam para transformar o cotidiano em conhecimentos ambientais metódicos e significativos para Os estudantes.

No nosso entendimento não basta apenas levar os estudantes para conhecer as adjacências da escola. É necessário que o professor possua fundamentos concretos, suficientes para esclarecer o estudante em relação as paisagens e os problemas visto durante as aulas prática e a partir dessa interação possa conduzir o deiscente a refletir de forma crítica sobre as problemáticas ambientais e socioambientais que Ihes cercam e, por conseguinte consigam individualmente e coletivamente encontrar soluções para aquelas problemáticas que mais lhes incomodam.

Isto nos levou a perceber que a Nova LDB Lei n. 9.394/96 e os Parâmetros Curriculares Nacionais proporcionaram certa autonomia para que as escolas possam trabalhar a questão ambiental de forma interdisciplinar, mas nem a escola e nem os professores estavam preparados para interagir dentro da nova compreensão, concretizando-a na prática. Um exemplo disso é a grande dificuldade que os gestores, pedagogos e professores têm em construir, de forma interdisciplinar, os seus projetos políticos pedagógicos e os seus planos de ensino. Em parte, isto se deve à falta de condições salariais, pedagógicas e políticas, resultado de um fenômeno que tem feito com que as reformas educacionais brasileiras de certo modo permaneçam apenas no plano real. 


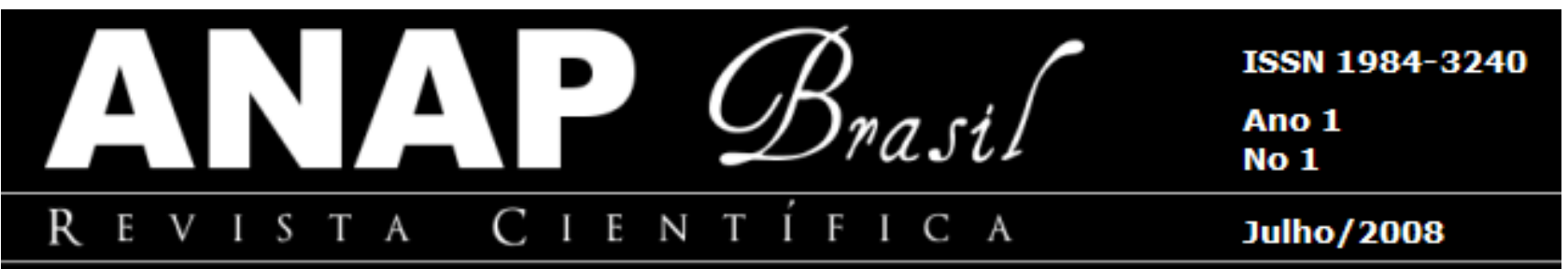

\section{METODOLOGIAS UTILIZADAS PELOS PROFESSORES ANTES DE CURSAREM 0 MÓDULO DE EDUCAÇÃO AMBIENTAL}

Conhecer bem o assunto que ensina e saber definir metodologias significativas de trabalho são princípios básicos indispensáveis que o professor precisa possuir para poder proporcionar nos estudantes a aprendizagem de qualquer conteúdo.

Uma grande maioria dos professores em formação afirmou trabalhar as questões ambientais de forma transversal e interdisciplinar, mas, ao especificarem as suas respostas, aqueles professores mostraram-se confusos em relação aos significados, às dimensões e às práticas desses enfoques, deixando claro ao mesmo tempo, que trabalham esses assuntos isoladamente nas diferentes disciplinas.

O caráter transversal da educação ambiental se apresenta em três dimensões no âmbito formal; a saber: conceitual, institucional e pedagógico. Neste Sentido define-se que a educação ambiental deve estar presente em todas as matérias ou áreas de conhecimento do currículo escolar e também na organização dos conteúdos e da aprendizagem.

Do ponto de vista conceitual, entendemos que o meio ambiente não pode ser reduzido apenas às questões que afetam a biosfera ou relacionadas somente com as mudanças climáticas, com a devastação das florestas, com a contaminação das águas ou com a extinção de inúmeras espécies de animais, mais que ao mesmo tempo envolve também as relações políticas, econômicas e culturais, configurando-se assim a chamada sociosfera. É nesse âmbito que se originam os fenômenos que denominamos de problemas ambientais, além de outros, como os de saúde, consumo e até de discriminação em razão de raça e sexo.

Para entender e trabalhar a problemática ambiental ou socioambiental de forma transversal precisamos também entender como se dá a distribuição dos alimentos, os problemas demográficos, o funcionamento do sistema econômico atual. Pois, como já dissemos, todas essas questões envolvem a problemática ambiental. 


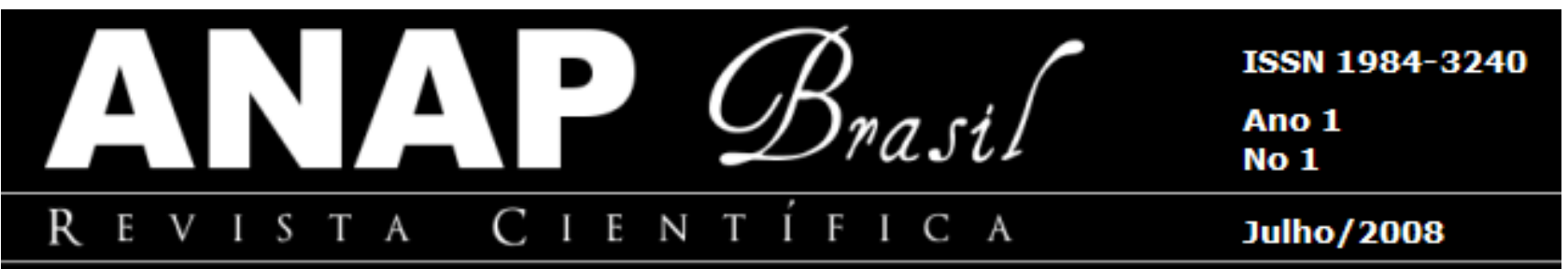

A dimensão institucional da transversalidade se define pela tomada de consciência das instituições políticas, no sentido de criar planos nacionais, estaduais e municipais de meio ambiente e estratégias de viabilização da educação ambiental.

A dimensão pedagógica, ou de desenvolvimento curricular, tem por objetivo proporcionar a escola e as novas gerações a formação de novos valores e novas atitudes que estão na base da educação ambiental, como também aos novos conceitos e procedimentos complexos que se desenvolvem no seio da problemática ambiental e do novo paradigma ambientalista.

Mas por outro lado muitos autores reconhecem que existe uma série de insuficiências da transversalidade, entre elas a,

Desse modo, somos levados a entender que a prática da transversalidade em relação à questão ambiental deve resultar de um funcionamento sólido entre a tripla dimensão da transversalidade da educação ambiental. Significa, então, dizer que não haverá evolução da dimensão pedagógica se não houver progresso da dimensão conceitual e se os professores e a sociedade continuarem percebendo a questão ambiental apenas nos seus aspectos ecológico e de preservação, e se não conseguem perceber os aspectos socioambientais. Também não haverá desenvolvimento da dimensão pedagógica se não existir um Plano Nacional de Meio Ambiente, se o sistema educacional não criar estratégias capazes de implementar a educação ambiental, oferecendo condições para que os professores possam estudar e, por conseguinte melhorarem as suas práticas de ensino, tanto dentro como fora da escola.

Portanto, a transversalidade é um processo que deve ser construído. Dessa construção deve resultar uma nova mentalidade em torno do conceito de meio ambiente, nova mentalidade política e uma nova prática dos professores e da sociedade em relação à questão ambiental. Significa dizer que a transversalidade só se torna possível se se estender desde a lei até ao programa de estudos, representando o contexto institucional, que compreende desde uma formulação constitucional até uma lei de reforma educativa.

Para isto os conteúdos ensinados pelos professores devem ser construídos e definidos por três características:

- Devem ser conteúdos surgidos da própria realidade dos alunos. Mas, para que as mudanças possam acontecer, faz-se necessário que os professores e os discentes 


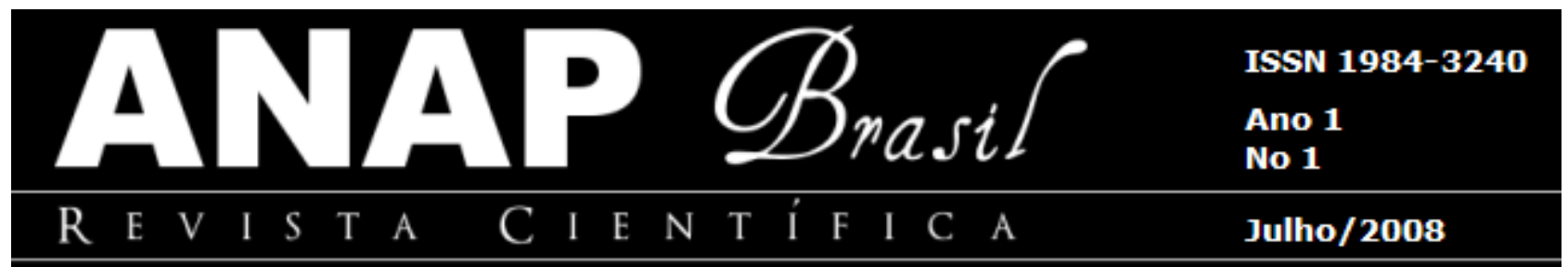

sejam capazes de transformar as suas realidades cotidianas em conhecimentos científicos, que saibam fazer o caminho de volta ao cotidiano e ao científico, numa constante ressignificação dos seus problemas sociais;

- São conteúdos elaborados a partir de uma profunda análise compreensiva da realidade em que vive a comunidade, de modo a levar os sujeitos envolvidos no contexto à aquisição de novas atitudes em relação ao meio ambiente, e, por conseguinte consigam melhorar as suas realidades;

- Os conteúdos devem ser construídos dentro das diferentes áreas curriculares, não de forma artificial, mas como parte concreta do planejamento de ensino e aprendizagem servindo de ponte com a realidade, e com os problemas sociais que envolvem a sociedade; Como mostramos na figura abaixo.

Ilustração 1: Temas transversais sobre meio ambiente e educação

As discussões feitas em torno dos temas transversais nos levaram a entender que o trabalho interdisciplinar em relação ao meio ambiente só pode acontecer de forma concreta a partir da forma como os professores entendem e trabalham esse tipo de assunto na forma transversal.

A problemática ambiental da forma complexa como se apresenta exige a integração das diversas disciplinas científicas e técnicas como meio de encontrar explicações e sua resolução.

\footnotetext{
A interdisciplinaridade, portanto, é a forma de superar a visão fragmentada do currículo como "somatório ou confluência de algumas poucas imbricações, formadas quase sempre em torno de disciplinas nucleares, que indiquem a 'espinha dorsal' de cada curso" E de superar a tendência à hierarquização das disciplinas segundo sua suposta maior ou menor importância (SAVIANI, 1998, p. 42).
}

A complexidade que envolve a questão ambiental atual exige que os professores entendam e trabalhem os conhecimentos ambientais de forma interdisciplinar, pois entendemos ser esta a filosofia de trabalho capaz de oferecer aos discentes uma nova dimensão epistemológica da questão ambiental, a partir da qual professores e estudantes 


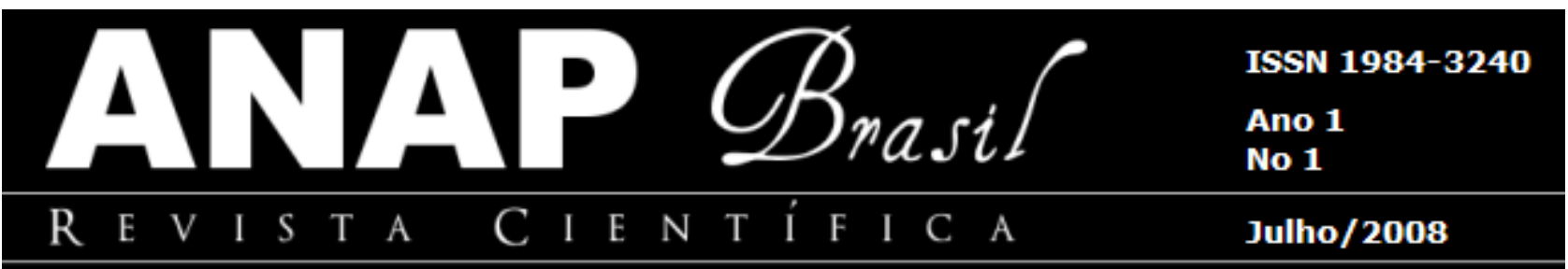

possam romper de forma crítica os limites existentes entre as disciplinas, ampliando os seus conhecimentos e as suas visões de mundo. Numa idéia interdisciplinar, torna-se evidente a necessidade de um currículo integrado que valorize o conhecimento contextual no qual as várias disciplinas sejam vista como recursos a serviço de um objetivo central (SARABIA, 2004 p.88).

Entendemos também que este processo não se dá de forma imediata, é uma prática construída a partir das nossas vivências, da postura que assumimos e da atitude que tomam em relação aos problemas ambientais que incomodam a sociedade.

Abordar a interdisciplinaridade como atitude supõe entender que ela exige e ao mesmo tempo, permite:

- Que professores e estudantes superem as suas visões fragmentadas que colocam barreiras entre as disciplinas, entre os diferentes conhecimentos;

- Que professores, estudantes e a sociedade de modo geral precisam estar dispostos para romper barreiras nas suas diferentes funções, como também precisam estar dispostos a modificar seus antigos hábitos ambientais;

- Que os professores estejam engajados pessoalmente, isto é, tenham convicção política do tipo de homem e de mulher que pretendem formar para sua sociedade e também estejam dispostos a aceitar os limites do próprio saber e abertos para acolher contribuições de outras disciplinas, visto que ninguém jamais domina todos os conhecimentos;

a Que professores e estudantes superem as suas individualidades, que possam trabalhar em prol da coletividade e numa constante forma dialogal possam superar as problemáticas ambientais e socioambientais dos seus dia-a-dia;

- Que professores e estudantes estejam dispostos ao exercício da dúvida, não no sentido de desacreditar em todo o conhecimento ambiental que já está posto à sociedade, mas acreditar que é possível sociabilizar os saberes já elaborados e construir novos conhecimentos. Para isto, ambos precisam cultivar a curiosidade, pois é um dos requisitos básicos para que estejam sempre desejosos pala prática da pesquisa e pela descoberta, conscientes da necessidade que se tem de formar o homem na sua totalidade, na sua essência, como um "ser no mundo" sujeito 


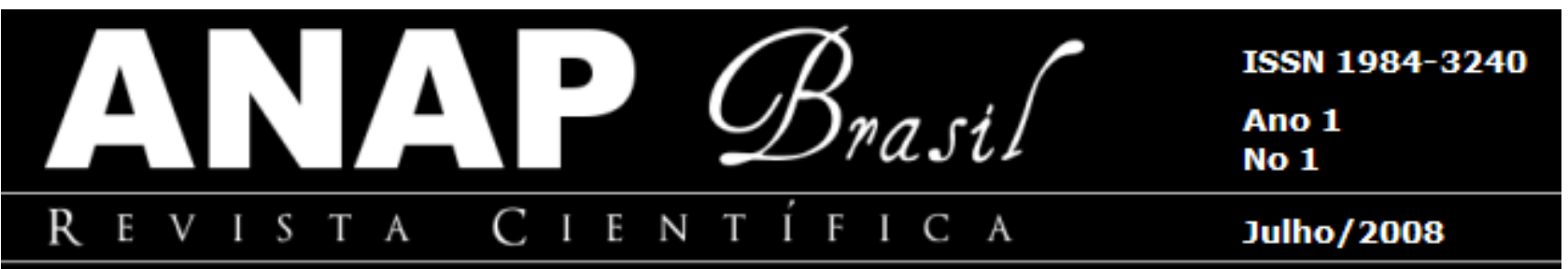

capaz de construir os seus próprios destinos dentro do processo de complexidade que envolve a sociedade local.

O jogo da complexidade se coloca como um enorme e constante desafio aos professores em formação, pois precisam, urgentemente, refletir sobre a forma como estão construindo os conteúdos, trabalhando e avaliando as questões ambientais com os estudantes, considerando-se que construir conteúdo, trabalhar e avaliar novos saberes numa sociedade complexa globalizada significa destruir conhecimentos universais concebidos como prontos e acabados. Isto, sem dúvida, deve influenciar nas práticas pedagógicas e metodológicas dos professores que precisam estar habilitados e, ao mesmo tempo, precisam ter autonomia para lidar com diferentes fórmulas de jogar com os conhecimentos que ensinam. Como também influenciará no comportamento dos estudantes que até então possuíam uma cultura a, b ou c em relação ao meio ambiente, isto é, estavam habituados a receber os conhecimentos de forma aleatória, sem questionar a utilidade destes nas suas vidas cotidianas.

Por outro lado, precisamos entender que reservas naturais amazônicas estão sendo exploradas de forma indiscriminada. De certo modo, isto tem gerado um comprometimento não somente dos aspectos físicos ou biológicos, mas principalmente dos fatores sociais, econômicos e políticos da região.

Diante disso, entende-se que o ambiente, e, principalmente, o amazônico, não pode ser considerado objeto de estudo de uma disciplina, isolado de outros fatores. Ele deve ser abordado a partir de uma dimensão holística, capaz de sustentar todas as atividades da Educação Ambiental, de modo a envolver e impulsionar os aspectos físicos, biológicos, sociais e culturais dos seres humanos que habitam na Região Amazônica.

Por este motivo, entende-se que o trabalho com temas geradores pode contribuir em muito na construção de uma mentalidade transformadora em relação ao meio ambiente.

\section{A CONCEPÇÃO DOS PROFESSORES SOBRE MEIO AMBIENTE APÓS CURSAREM O MÓDULO DE EDUCAÇÃO AMBIENTAL}




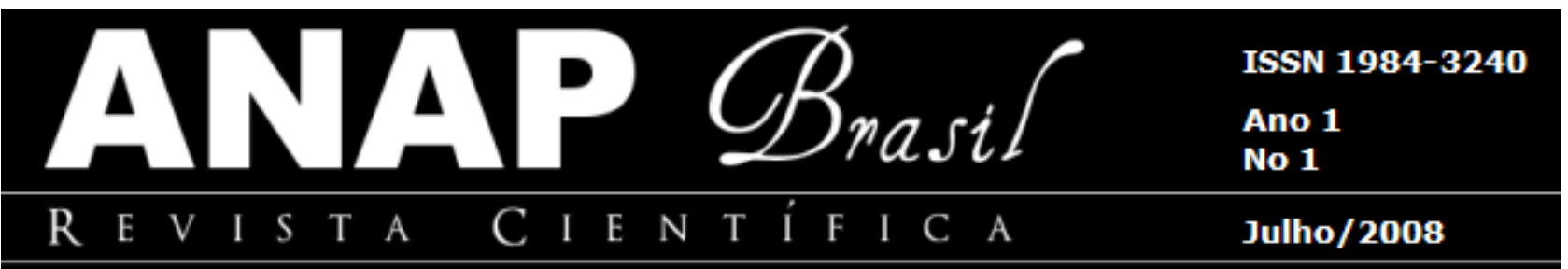

Ao contrário da primeira fase, em que os professores em formação assumiram uma posição antropocêntrica em relação ao meio ambiente, agora a maioria passou a assumir uma postura biocêntrica. Nesta concepção, os seres humanos percebem-se indissociáveis de seu entorno, compartilhando-o com os demais seres vivos, e aos quais se unem por interesses comuns, isto é, as pessoas não estão alheias aos seus entornos, como também não estão excluídas dos seus princípios de identidade.

A mudança de concepção dos professores em relação à questão ambiental se deve aos conteúdos $\mathrm{e}$ as metodologias utilizadas pelos professores titulares na ministração do módulo de Educação ambiental.

O fato de terem mudado é muito importante diante da urgente necessidade que se tem de desconstruir a racionalidade capitalista dominante que dá conta de todas às ordens sociais na atualidade e a continuação da construção de uma nova racionalidade ambiental que dê conta da problemática ambiental do nosso povo na sua forma real.

Assim entendemos que a compreensão da estrutura socioambiental, como também os aspectos históricos são componentes importantes, principalmente no momento de planejamento das ações e atividades ambientais. Não é suficiente a construção de ótimas pesquisas e excelentes relatórios das problemáticas socioambientais se grande parte da população inclusive muitos professores, não possuem uma compreensão formada sobre o significado de meio ambiente. Pois só podem valorizar a questão ambiental a partir do momento que podem também entendê-la.

Isto remete aos professores e a educação ambiental a necessidade de encontrar fórmulas através das quais as pessoas possam se tornar esclarecidas e, assim, poderem de forma consciente e cidadã, opinarem sobre projetos de meio ambiente que possam modificar as suas vidas e de suas comunidades.

Diante disso, precisamos, de forma urgente, ensinar as nossas crianças que o meio ambiente não se resume apenas aos fatores que nos rodeiam como entendiam os professores no início desta pesquisa.

O meio ambiente se constitui também do processo histórico e cultural que a humanidade vem construindo ao longo do tempo. Isto se coloca como uma importante 


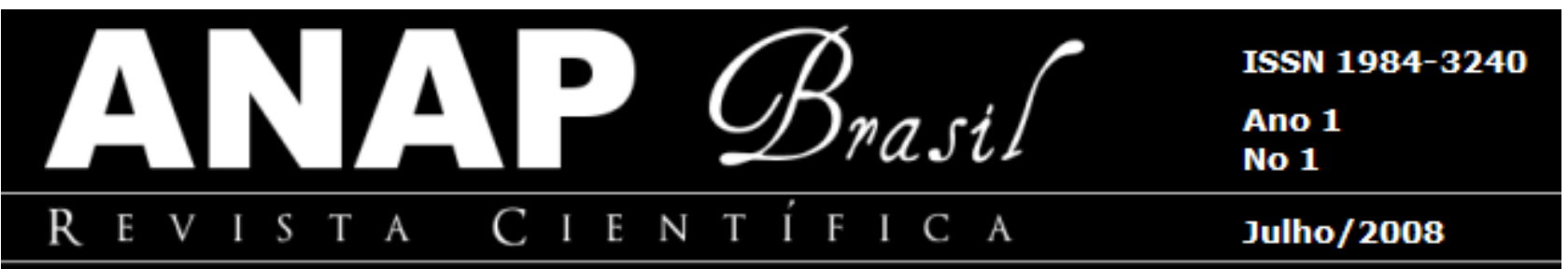

necessidade que cada sujeito da sociedade tem de se perceber como parte do meio ambiente. Pois entendemos que toda e qualquer mudança de atitude a ser tomada pelos indivíduos em relação às problemáticas socioambientais que lhes incomodam como: a exclusão social, as explorações indevidas dos recursos naturais, elas só poderão acontecer de forma concreta a partir do momento em que esses indivíduos se sintam e se vejam como parte integrante do meio ambiente e, de forma harmoniosa com a natureza, possam traçar os seus planos ambientais de sustentabilidade.

Acreditamos que essa nova postura possa contribuir profundamente na construção de novos paradigmas de desenvolvimento, tendo como princípios norteadores a eqüidade política, econômica, social e a prática constante do desenvolvimento sustentável, sem o qual nos parece ser impossível conceber melhores condições de sobrevivências para os amazônidas que vivem em condições de excluídos ou abaixo da linha de pobreza. Uma realidade que se contrasta com um potencial de riquezas que não se pode encontrar em outros lugares do mundo. "O Amazonas é uma Região com dimensão continental, com imensa diversidade cultural e um enorme potencial de riquezas naturais" (VIEIRA, 2005, p. 15).

\section{A INFLUÊNCIA DO MÓDULO DE EDUCAÇÃO AMBIENTAL NA FORMA DOS PROFESSORES PERCEBEREM AS PROBLEMÁTICAS AMBIENTAIS}

Diante dos resultados obtidos é possível observou-se que em relação à primeira fase da pesquisa houve considerável mudança na forma dos professores em formação conceberem as problemáticas ambientais da atualidade.

Os conteúdos da disciplina, as metodologias, a forma como estes foram trabalhados, todo o processo foi construído com o propósito de possibilitar aos professores em formação construírem uma nova forma de pensar a problemática ambiental. Porém ficou evidente que o tradicionalismo ambiental, o ecologismo e o conservadorismo ainda dominam as práticas educacionais e a forma daqueles profissionais conceberem o meio ambiente, como também a pouca convivência que 


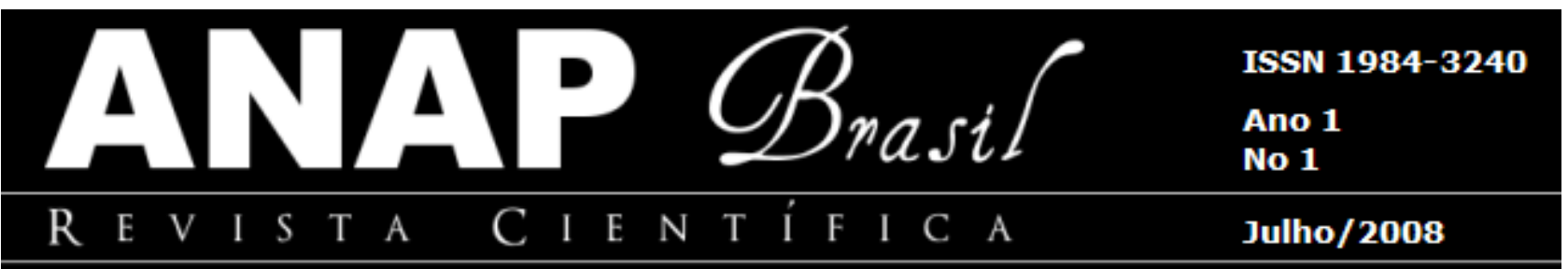

possuíam com esse tipo de assunto e com a nova legislação de educação ambiental. Isto fica patente quando alguns professores afirmam que a disciplina não causou mudanças em suas vidas profissionais, quando quarenta e cinco daqueles docentes demonstram não ter um pensar mais definido sobre a problemática ambiental e até resistem mudar as concepções e as suas práticas ambientais. Este fenômeno se deve ao fato do pouco conhecimento que os professores em formação possuíam sobre esse assunto.

Isto, de certo modo, impede a construção e a reconstrução de valores, hábitos e novas atitudes frente às problemáticas ecológicas e socioambientais que incomodam a sociedade global e local. Mas mesmo assim, é possível "que existe uma luz no fim do túnel", basta refletir sobre a resposta que esses últimos deram: "Descobri que posso melhorar a minha colaboração com a questão ambiental". Isto nos faz perceber que os professores que deram essas respostas, apesar de não terem adquirido um pensar mais amplo sobre o meio ambiente no decorrer do curso, de alguma forma os conteúdos trabalhados no módulo Ihes incomodaram, levando-os a descobrir que precisam estudar mais sobre a questão ambiental e participar de forma ativa das problemáticas ambientais.

"Deve haver uma outra forma de desenvolvimento, que não seja esta de devastar a natureza", os professores que fizeram esses comentários demonstraram estar com dúvida em relação ao meio ambiente. Significa que não conseguiram formar um pensamento mais concreto sobre uma outra forma de desenvolvimento ambiental, mais desconfiam que deve existir uma outra forma. Isto a nosso ver é de fundamental importância na trajetória acadêmica de qualquer estudante, pois é a partir do momento que se passa a desconfiar que existe algo errado, é que as pessoas buscam conhecer e, por conseguinte tentar corrigir o erro.

\section{A CONTRIBUIÇÃO DO MÓdULO DE EDUCAÇÃO AMBIENTAL PARA A FORMAÇÃO DOS PROFESSORES}

Para $99 \%$ dos professores em formação, o módulo de Educação Ambiental possibilitou-Ihes maior segurança em relação à questão Ambiental. 


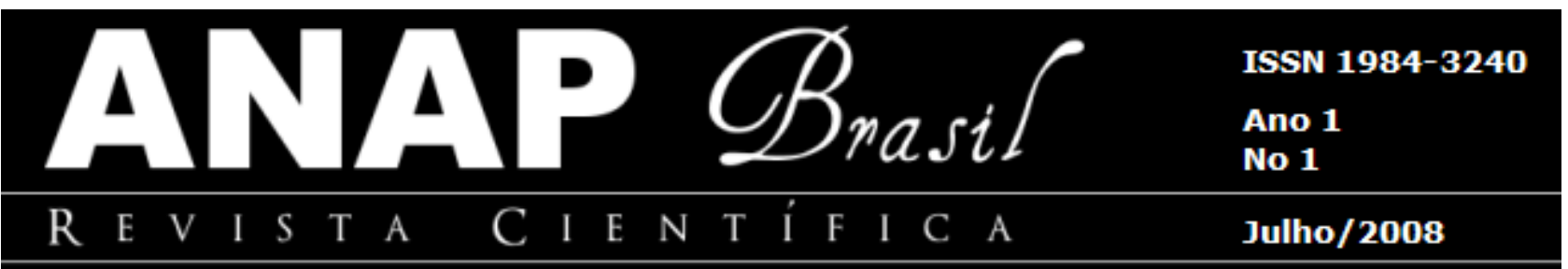

O fato dos professores em formação estarem mais seguros sobre a questão ambiental e terem ampliado as suas visões sobre essa problemática pode ser considerado como uma grande contribuição do módulo de Educação Ambiental, na formação daqueles profissionais, considerando-se que na primeira fase da pesquisa a maioria daqueles discentes demonstraram total insegurança ao receberem o questionário abordando a questão ambiental.

Em torno de $100 \%$ deles diziam saber poucas coisas sobre esse assunto, motivo pelos quais muitos professores responderam as questões baseando-se apenas no senso comum, numa demonstração própria de que possuíam poucos conhecimentos sobre a nova legislação ambiental.

A Constituição Brasileira, Os Parâmetros Curriculares Nacionais e a Nova Lei de Diretrizes e Base da Educação Nacional Lei n. 394/96. Ao mesmo tempo também demonstraram ter poucos conhecimentos sobre transversalidade e interdisciplinaridade, pois em nosso entender, a falta desses saberes dificulta, em grande parte, a construção de uma compreensão real e racional dos professores em relação à questão ambiental, como também dificulta a forma daqueles profissionais trabalharem esse tipo de conteúdo com os seus aprendizes das Séries Iniciais do Ensino Fundamental.

Essa falta de compreensão da problemática ambiental, como também a compreensão fragmentada do saber ambienta, é a causa porque um grande número de professores se deteve em responder coisas que não estavam relacionadas com o assunto, onde apenas $1 \%$ foi capaz de afirmar que a disciplina em nada mudou na sua formação.

\section{TEMÁtICAS TRABALHADAS PELOS PROFESSORES EM FORMAÇÃO NA CONCLUSÃO DO MÓDULO DE EDUCAÇÃO AMBIENTAL}

As temáticas escolhidas pelos professores em formação nos causaram supressas, A maioria optou trabalhar com aquelas relacionadas à preservação dos igarapés poluídos da cidade de Manaus a coleta e reciclagem do lixo nas escolas de Ensino Fundamental. 


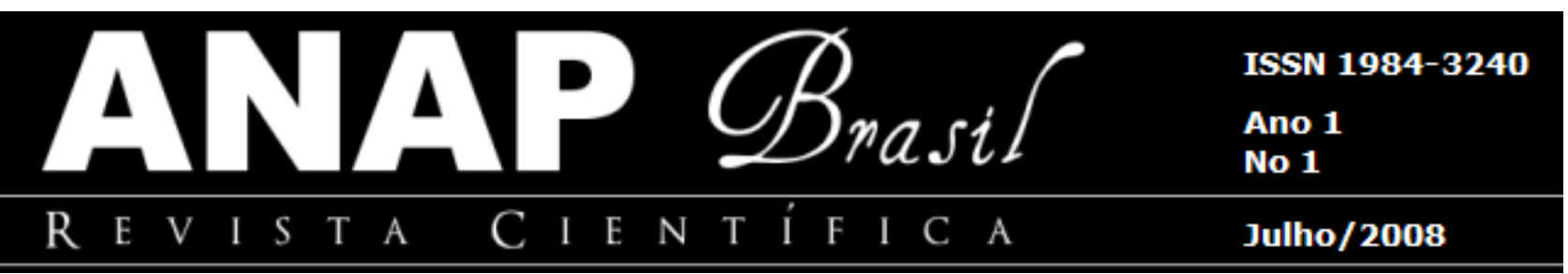

Este fenômeno se estendeu por todas as salas de aulas do projeto PROFORMAR, incluindo a sala do próprio professor responsável pela pesquisa, onde $70 \%$ dos trabalhos práticos abordaram os aspectos de preservação, e conservação, apesar das insistentes intervenções do pesquisador com a finalidade de esclarecer aos professores em formação que a questão ambiental não se restringe apenas aos problemas de conservação e preservação, e que não poderiam deixar de abordar a problemática socioambiental que envolve a sociedade amazonense.

Diante dessa panorâmica, observa-se que os professores mudaram, de certa forma os seus discursos em relação à problemática ambiental, pois em momentos anteriores da pesquisas muitos docentes chegaram a afirmar que o módulo de educação ambiental mudou as suas maneiras de ver a problemática ambiental. Agora podiam perceber essa problemática não só como uma questão de preservação e conservação, mas como uma questão socioambiental. Mas, como acabamos de constatar, essa postura não é assumida na prática pelos professores em formação, ficando assim caracterizado que muitos ainda resistem ao processo de mudança.

Isto nos faz perceber que a mudança nas práticas dos professores em formação, em relação à problemática ambiental, não pode ser vista como um fenômeno que deve acontecer do dia para a noite, isto é, após o término da disciplina educação ambiental ou de um único trabalho prático de meio ambiente.

A mudança nas práticas ambientais dos professores e uma visão mais holística sobre esse assunto não surgirá casualmente, devem ser construídas a partir da capacidade e disponibilidade reflexiva que os professores devem adquirir, nas pesquisas e em outras experiências concretas que aqueles profissionais devem desenvolver nas suas próprias trajetórias docentes com a problemática ambiental.

\section{A INFLUÊNCIA DO MÓDULO DE EDUCAÇÃO AMBIENTAL NA PRÁTICA DOS PROFESSORES EM FORMAÇÃO}




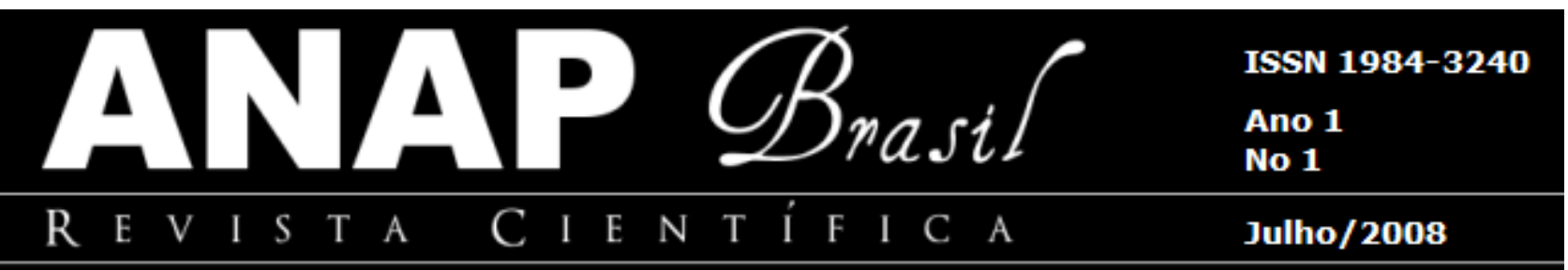

Após cursarem o módulo de Educação Ambiental alguns professores fizeram os seguintes relatos:

"Ampliaram o conhecimento e a consciência crítica em relação à questão ambiental".

"Podem trabalhar a preservação da natureza de forma dialogal".

"Despertaram para a necessidade da pesquisa e de uma maior atuação em relação à educação ambiental".

"Descobriram que é possível trabalhar a questão ambiental de forma interdisciplinar".

Sentiram-se mais seguro para trabalhar a questão ambiental.

Ao comparamos as mudanças ocorridas na forma de pensar e trabalhar as questões ambientais propostas pelos professores na fase anterior da pesquisa observamos que eles mudaram consideravelmente, não o quanto esperávamos. Ao mesmo tempo observamos também que o campo de atuação da educação ambiental avançou. Resultado disto é a própria realização do módulo de educação ambiental no projeto PROFORMAR.

Isto remete um desafio aos fazeres pedagógicos dos professores, pois precisam estar capacitados coletivamente para se engajarem em novas linhas de atuação, para construir conteúdos e novas formas de agir com os seus alunos das séries iniciais e com a sociedade de modo geral em relação ao meio ambiente que mesmo diante de perspectivas não muito promissoras nos possibilite a conquista de novos horizontes.

\section{ANÁlise dAS ATIVIDADES PRÁtICAS REALIZADAS PELOS PROFESSORES EM FORMAÇÃO NO FINAL DO MÓDULO DE EDUCAÇÃO AMBIENTAL}

Ao término da disciplina os professores titulares aplicaram atividades práticas para serem desenvolvidas em grupo de no máximo cinco professores em formação. 


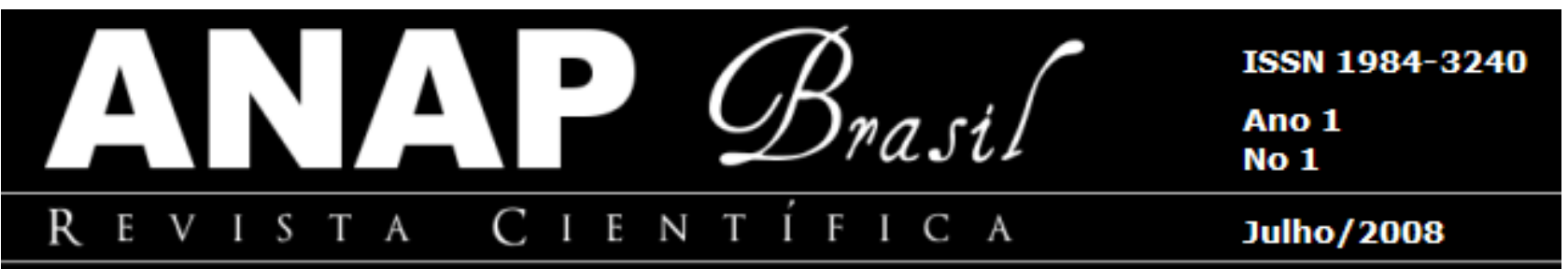

O objetivo da atividade prática era perceber se os conteúdos da disciplina e a forma como foram ensinados haviam provocado mudanças na concepção dos professores em relação ao meio ambiente e nas suas práticas escolares.

Ao conferir as temáticas desenvolvidas e aplicadas nas escolas do Ensino Fundamental pelos docentes em formação, foi possível constatar que em torno de $90 \%$ e 97\% dos professores trabalharam as temáticas como a limpezas dos igarapés da cidade, a reciclagem do lixo da escola e a conservação dos mananciais, isto é, continuam ignorando a dimensão socioambiental, também nos levaram a perceber que de certo modo ainda continuam se comportando de forma antropocêntrica em relação ao meio ambiente, pois não conseguem se ver como incluídos no ambiente. Estão percebendo apenas aqueles aspectos que ficam lá adiante, como os igarapés, os mananciais e outros.

Esses números impressionam e colocam interrogações a quem de interesse for sobre a metodologia do curso em questão, visto que muitos professores afirmam que aprenderam os conteúdos ensinados.

Portanto, se aprenderam os conteúdos, porque então não mudaram as suas práticas escolares em relação às problemáticas ambientais. Por que, alguns professores em formação ainda continuam jogando o lixo que produzem no chão da sala de aula?

Assim, ficou demonstrado que de certa forma muitos professores apenas passam pelos conteúdos, mais isto não foi suficiente para que mudassem os seus hábitos e as suas práticas ambientais escolares. A atividade prática que desenvolveram também não foi suficientemente vivenciada para que aqueles docentes conseguissem mudar.

O curso foi de suma importância na formação dos professores, porém, estes resultados remetem não só à coordenação daquele curso, mas a todos os responsáveis por outros cursos e pelo processo educativo de modo geral, da importância de se criar pedagogias que viabilizem um melhor dinamismo na relação teoria e a prática, de modo que não há mudança de postura e procedimento enquanto a experiência não for vivida pelos sujeitos.

Não posso entender os homens e as mulheres, a não ser mais do que simplesmente vivendo, história, cultura e socialmente existindo, como seres fazedores de seu "caminho" que, ao fazê-lo, se expõem ou se entregam ao "caminho" que estão fazendo e que assim os refaz também (FREIRE, p. 97). 


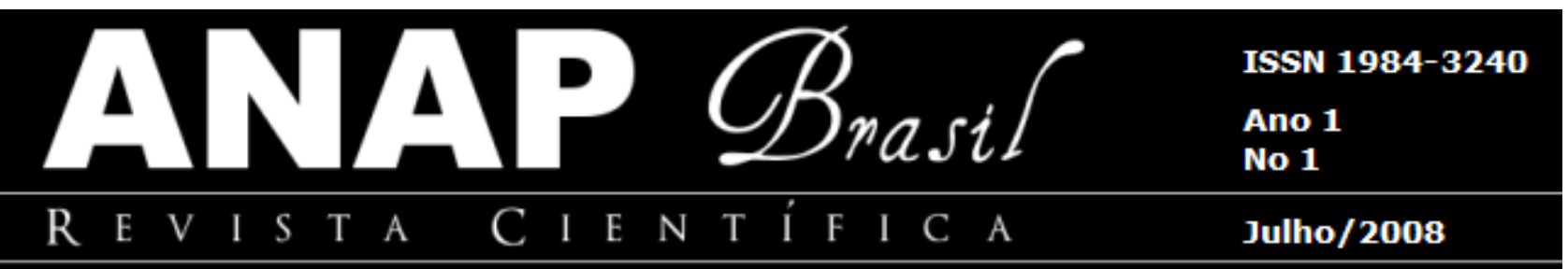

Fazer e se entregar ao caminho que estamos construindo significa estarmos conscientes politicamente do tipo de sociedade que queremos formar. Isto depende dos desafios das pesquisas que podem ser desenvolvidas, das metodologias aplicadas, da disposição que temos de incomodar e ser incomodados frente a complexidades dos novos destinos que traçamos para nossa sociedade.

Se o conhecimento não nos desinstalar da poltrona confortável da acomodação irrefletida, não é digno deste nome. O sentido último do conhecimento que nos dignifica como sujeitos é justamente a desinstalação e o espanto que lançam cada ser humano, em particular, de outros significados que transformam nosso modo de ser no mundo ( GHEDIN, 2002 , p. 143).

Estas reflexões nos fazem entender que o conhecimento e as práticas ambientais precisam ser construídos pelo próprio povo que aqui vive, a partir das necessidades, da cultura, da história e das suas especificidades. Isto, sem dúvida, motivará a capacidade criativa de nossa sociedade que ao longo da história da Amazônia sempre recebeu os conhecimentos prontos, acabados e determinados.

\section{CONCLUSÃO}

$\mathrm{Na}$ busca de compreender as representações e as práticas educacionais ambientais dos professores em formação do projeto PROFORMAR da Universidade do Estado do Amazonas nos defrontamos com um quadro de muitas indefinições e contradições em relação à concepção daqueles docentes sobre meio ambiente, sobre as problemáticas ambientais e as suas práticas pedagógicas com os estudantes das Séries Iniciais do Ensino Fundamental.

Entende-se que isto se deve ao fato da educação ambiental ainda ser um tema que se encontra em pleno estágio de elaboração. Por este motivo, para muitos daqueles professores em formação este foi o primeiro contato acadêmico que tiveram com este tipo de conhecimento. Um fenômeno que ficou muito claro na apresentação dos resultados desta pesquisa. 


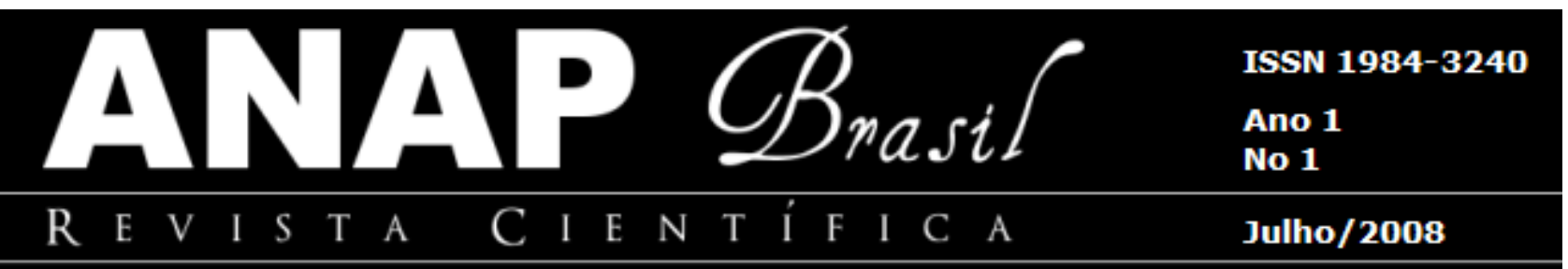

Supõe-se que neste momento aqueles docentes já tiveram a oportunidade de fazer outras reflexões sobre os conhecimentos ambientais que adquiriram no Curso Normal Superior.

Portanto, concorda-se que as questões ambientais aqui abordadas e explicadas não podem ser consideradas prontas e acabadas, pois se trata de representações e práticas de profissionais que estão nascendo para uma das problemáticas mais complexas da atualidade. Portanto, as suas experiências com a questão ambiental não foram suficientes para que eles construíssem novos saberes e novas práticas pedagógicas. Mesmo assim, acredita-se que esta pesquisa poderá fornecer subsídios teóricos e metodológicos para outros cursos e outras pesquisas que possam ser realizadas em relação ao meio ambiente e as problemáticas ambientais.

Diante de tantas indefinições recomenda-se aos educadores de modo geral e ao sistema educacional que possam dá maior ênfase nas pesquisas educacionais e nos trabalhos práticos em relação à Educação Ambiental, possibilitando aos professores em formação, aos estudantes do Ensino Fundamental e do Ensino Médio e à sociedade de modo geral, que não apenas estudem ou passem pelos conteúdos. Que sejam viabilizados meios e recursos para que os estudantes e todas aquelas pessoas envolvidas com a Educação Ambiental tenham condições de apreender os conteúdos de meio ambiente e também de vivenciar experiências práticas relacionadas com o meio onde elas próprias estejam inseridas. De modo que se sintam motivadas para um envolvimento maior com essa questão e também responsáveis pela solução das problemáticas ambientais e, por conseguinte, pela construção de uma sociedade mais humana e mais justa.

\section{REFERÊNCIAS}

BOFF, Leonardo. Terra: à volta a terra como pátria comum. São Paulo: Ática, 1995. BRASIL. Lei de Diretrizes e Base da Educação Nacional lei n. 9. 394/96. 


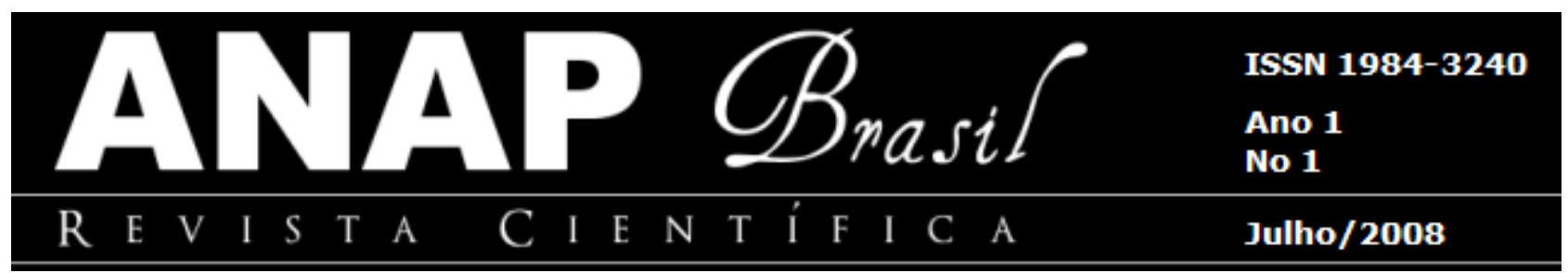

FREIRE. Paulo. A pedagogia da esperança. Um reencontro com a pedagogia do oprimido. Rio de Janeiro. Ed. Pedagógica e Universitária 1992.

GHEDIN. Evandro. Professor reflexivo: da alienação da técnica à autonomia da crítica In: PIMENTA, e GHEDIN (Orgs.). Professor reflexivo no Brasil: Gênese e crítica de um conceito. São Paulo: Cortez, 2002: 130 - 141 -143

LIBÃNEO, José. Reflexibilidade e formação de professores: outra oscilação do pensamento pedagógico brasileiro. In PIMENTA e GHEDIN (Orgs). Professor Reflexivo no Brasil: Gênese e crítica de um conceito. São Paulo: Cortez 2002.

SARABIA, Raul. Educação Ambiental nas escolas rurais do município de Manaus In ANJOS, Alair; BEZERRA, Aldenice; GREGÓRIO Jorge; SARABIA, Raul (Orgs) Educação Ambiental: estudo numa perspectiva para uma sociedade sustentável no município de Manaus. Manaus: EDUA, 2004, 88.

SATO, Michele. Educação Ambiental. São Carlos, SP: RIMA 2002.

SAVIANI, Nereide. Saber escolar, currículo e didática - Problemas da unidade conteúdo/método no processo pedagógico. São Paulo: Autores Associados, 1998.

VIEIRA. Ademar. (org) Perspectivas curriculares. Manaus. Editora BK 2005. 